
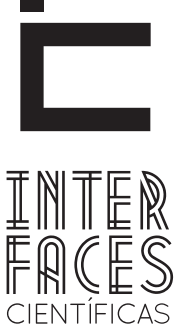

DIREITO

\title{
O MINISTÉRIO PÚBLICO E ASSEMBLEIA NACIONAL CONSTITUINTE: AS ORIGENS DE UM TEXTO INOVADOR
}

Mylene Comploier ${ }^{1}$

\section{RESUMO}

Considerando que recentemente houve o advento de comemoração dos 25 anos da promulgação da Constituição da República Federativa do Brasil, por alguns denominada de 'Constituição-cidadã', e que, nesse período, o Ministério Público brasileiro desenvolveu uma feição única no espectro mundial, em muito resultado do quanto preconizado no texto constitucional, útil neste momento trazer à colação informações já disponíveis, notadamente entrevistas, de modo obter-se uma ideia geral de como foi a preparação, atuação e conquistas do Ministério Pú- blico na Assembleia Nacional Constituinte (ANC) e, ao final, o desenho constitucional obtido, de modo a se questionar como foi possível a aprovação de um texto tão avançado, que superou até mesmo as expectativas da própria classe.

\section{PALAVRAS-CHAVE}

Constituição. Assembleia Nacional Constituinte. Ministério Público. Origens. 


\section{ABSTRACT}

Whereas recently there was the celebration event of the 25th anniversary of the promulgation of the Constitution of the Federative Republic of Brazil, by some called 'Constitution-citizen', and that in this period, the Brazilian Prosecution Office has developed a unique feature in the global spectrum in very recommended as a result of the constitutional text, useful at this point to bring into play information already available, notably interviews in order to obtain a general idea of how-was the preparation, performance and achievements of the Prosecution Office in the National Constituent Assembly (NCA) and at the end, the constitutional design obtained, to wonder how it was possible to approve such an advanced text, which exceeded even the expectations of the class itself.

\section{KEYWORDS}

Constitution. National Constituent Assembly. Prosecution Office. Origins.

\section{RESUMEN}

Mientras que hace poco no era el evento de celebración del 25 aniversario de la promulgación de la Constitución de la República Federativa del Brasil, llamado por algunos "Constitución-ciudadano", y que en este período, el Ministerio Público de Brasil ha desarrollado una característica única en el espectro global en muy recomendada como resultado del texto constitucional, útil en este punto para poner en información juego ya está disponible, en particular entrevistas con el fin de obtener una idea general de cómo-era la preparación, el rendimiento y los logros del Ministerio público en la Asamblea Nacional Constituyente (ANC) y al final, el diseño constitucional obtuvo con el fin de cuestionar cómo era posible aprobar un texto tan avanzada, que superó incluso las expectativas de la propia clase.

\section{PALABRAS-CLAVE}

Constitución. Asamblea Nacional Constituyente. Ministerio Publico. Orígenes. 


\section{INTRODUÇ̃̃O}

0 presente artigo teve por escopo perscrutar as informações disponíveis sobre a atuação do Ministério Público na Assembleia Nacional Constituinte (ANC). Assim, procurou-se obter dados, notadamente de fontes orais, sobre a agenda do Ministério Público para a ANC, tais como: quais itens que o Ministério Público gostaria de ver contemplados no texto; as pessoas que se mobilizaram nestes trabalhos, quais congressistas foram procurados, como se deu essa abordagem e quem eram os principais contatos no Congresso Nacional.

Também, procurou-se investigar quais alianças foram firmadas, quais propostas foram levadas para votação, quais as vitórias e quais as derrotas decorrentes dessa atuação. Ao final, procurou-se perscrutar sobre a avaliação do texto final da Constituição de 1988 por esses atores e como foi possível a aprovação de um texto tido como tão avançado no Congresso Nacional.

\section{A AGENDA DO MINISTÉRIO PÚBLICO PARA A AS- SEMBLEIA NACIONAL CONSTITUINTE [ANC)}

A partir do início do fim do governo militar, e com o advento de uma promessa de uma nova ordem constitucional, o Ministério Público percebeu a necessidade de não assistir esse processo de maneira estanque. As lideranças nacionais do Ministério Público se aperceberam de que essa nova ordem constitucional deveria ser proposta a partir de reflexões geradas pela própria instituição. Os promotores decidiram participar ativamente da construção dessa nova feição do Ministério Público.

O primeiro e decisivo passo foi participar do processo decisório (MAZZILLI, 2011, p. 26, grifo do autor):

[...] nós não queríamos que o Congresso Nacional ou uma Constituinte - específica ou não, isso nós não sabíamos o que viria -, nós não queríamos que eles propusessem um projeto de Ministério Público para nós, e nós ficássemos assistindo. Não; nós queríamos participar da construção dessa nova face do Ministério Público. 0 que fizemos? Nós começamos a mobilizar o Ministério Público brasileiro. Todo ele. Nós começamos a fazer campanha, nós começamos a ir aos jornais, a dizer "o promotor é o defensor do povo", porque nós sabíamos que havia uma aspiração para criar talvez um ombudsman fora da instituição. Nós começamos a criar um movimento de valorização do Ministério Público.

Fez parte desse primeiro passo a necessidade de se criar o que foi chamado de "uma consciência nacional' de Ministério Público, diante das inúmeras disparidades regionais até então existentes.

Os Ministérios Públicos do Brasil eram extremamente diferentes: em São Paulo já havia equiparação dos vencimentos do Ministério Público com os da Magistratura há muitos anos, mas o mesmo não acontecia em outros estados do Brasil; a Advocacia, embora em São Paulo não fosse admitida desde 1947 (assim como no Rio Grande do Sul e em Minas Gerais), o era, por exemplo, no Estado do Rio de Janeiro; também desde 1947, os Procuradores-Gerais eram, em São Paulo, escolhidos dentro da carreira (embora nomeados e demissíveis ad nutum); isso era diferente em outros Estados da federação e no Ministério Público da União, cujo chefe Procurador-Geral de Justiça poderia ser escolhido fora da carreira.

Não havia comunicação e cooperação entre Ministérios Públicos e não havia trabalho em conjunto. Ministério Público Federal e Ministério Público Estadual não se somavam - essa situação é ainda mais problemática, pois o Ministério Público Federal posteriormente atua em um processo no qual já houve atuação do Ministério Público Estadual.

Sobre essas diferenças entre Ministérios Públicos, Dal Pozzo, (2002, p. 5), em entrevista, recorda-se:

A partir daí, eu [Antonio Araldo] e o Fleury começamos a percorrer todos os Estados do Brasil, passando uma semana, dez dias, em cada Estado. Procuramos levar 
uma mensagem propositiva sobre o Ministério Público, porque nos Estados do Norte, ou do Nordeste, o Ministério Público simplesmente não existia, ou melhor, existia apenas no papel - ninguém sabia nem o porquê estava atuando num processo, a não ser na área criminal, que é muito evidente. Mas, na área cível quase ninguém sabia nem mesmo o que estava fazendo. Encontramos situações fantásticas, como, por exemplo, o Presidente da Associação do Ministério Público ser o Presidente da OAB! Isso ocorreu no Ceará. Eram coisas incríveis! No Amazonas constatamos que os promotores não tinham a menor notícia do que o promotor tinha que fazer no cível. Enfim, fomos não só levar essa mensagem, como também deixar material escrito e, ainda, como que abrindo, franqueando a vinda desses colegas [...] para olharem um pouco como era o funcionamento do Ministério Público de São Paulo.

E mais: havia uma vinculação muito forte da instituição com o Poder Executivo. Em São Paulo, a título de exemplo, o Ministério Público antes de 1988 era apenas uma unidade de uma das Secretarias de Estado, no caso a Secretaria da Justiça. O Secretário de Justiça que decidia o orçamento do Ministério Público. Nomeações, promoções e remoções eram atos do Governador que deveriam passar pela Secretaria da Justiça.

o Procurador-Geral era nomeado e demitido ad nutum, e em alguns Estados era escolhido fora dos quadros da carreira, assim como no Ministério Público da União. Não havia garantias, não havia inquérito civil ou ação civil pública, e a atuação da instituição era modesta e dependente do Poder Judiciário.

Segundo Plínio de Arruda Sampaio (2002), o Ministério Público era, na verdade, um apêndice do Poder Executivo.

Diante de todo esse quadro acima exposto é que se constatou a necessidade de se buscar a denominada consciência nacional de Ministério Público, ou seja, qual deveria ser o modelo ideal dessa instituição.

Um congresso em São Paulo ocorreu em meados de 1985 para discutir o tema "Ministério Público e Assembleia Nacional Constituinte".
Muito foi produzido ali em termos de teses. As discussões envolveram a questão das garantias, se o Ministério Público seria um órgão do Poder Executivo ou do Poder Judiciário, quais seriam as funções do Procurador-Geral etc.

Paralelamente a esse congresso, a Confederação Nacional do Ministério Público (CONAMP) enviou um questionário aos Promotores do Brasil, que questionava a opinião de seus membros sobre as principais questões que envolviam o cerne da instituição. Uma equipe formada por promotores de diversos Ministérios Públicos - composta por, dentre outros, Anísio Bispo dos Santos, do Mato Grosso do Sul, Antonio Araldo Ferraz Dal Pozzo, de São Paulo, Sérgio D’Andrea Ferreira, do Rio de Janeiro, Vladimir Giacomuzzi, do Rio Grande do Sul e Antonio Bassi, do Paraná - consolidou as principais ideias da classe sobre o tema Ministério Público, como por exemplo, a escolha do Procurador-Geral, se deveria ter mandato ou não, em qual capitulo da constituição o Ministério Público deveria ficar, quais seriam suas funções e garantias etc.

A partir daí, foi marcado um encontro para Curitiba, em junho de 1986, para reunir pela primeira vez, na história do Ministério Público, todos os Presidentes de Associação e todos os Procuradores-Gerais juntos. Todos os Estados enviaram representantes.

O Estado de São Paulo enviou cerca de dez representantes à Curitiba, mas dias antes, alguns de seus membros produziram algo importante - a consolidação do que já havia sido sintetizado pela CONAMP (teses do congresso + questionários) com o anteprojeto da Comissão Afonso Arinos, também conhecida por 'Comissão dos Notáveis', que igualmente havia feito um anteprojeto para o Ministério Público.

São Paulo uniu a consolidação da CONAMP, as teses do congresso de São Paulo e o anteprojeto da Comissão dos Notáveis e fez o denominado anteprojeto síntese, porque o Ministério Público da União não queria ter o 
mesmo perfil do Ministério Público dos Estados e isso poderia embaraçar algumas conquistas já existentes.

E São Paulo, segundo o relato de seus membros, foi para Curitiba com o anteprojeto síntese em mãos, por intermédio de cerca de dez pessoas que fizeram parte desta comitiva, podendo ser citados Hugo Nigro Mazzilli, Walter Paulo Sabella, Antonio Araldo Ferraz Dal Pozzo, Cláudio Ferraz de Alvarenga, Luiz Antonio Fleury Filho, Paulo Salvador Frontini, Tilene Almeida de Moraes, Moacyr Antonio Ferreira Rodrigues, Antonio Augusto Mello de Camargo Ferraz, José Emmanuel Burle Filho, Pedro Franco de Campos e Renato Martins Costa.

Assim, foi posta aos presentes uma questão preliminar - a votação do anteprojeto síntese fruto da consolidação acima mencionada - como ponto de partida para as discussões sobre o ideal de Ministério Público. A questão preliminar foi votada e os presentes aceitaram iniciar a discussão a partir da consolidação desse anteprojeto. Foram três dias de intensa discussão sobre diferentes aspectos, que resultou na chamada Carta de Curitiba, como se recorda Hugo Mazzilli em entrevista concedida a Gunter Axt (MAZZILLI, 2002).

A preocupação foi a de apresentar um anteprojeto, pela liderança nacional do Ministério Público, com o máximo de harmonia e fruto do consenso, para que os atores responsáveis pelo ‘corpo-a-corpo' entrassem na Constituinte, falando a mesma linguagem.

Algumas matérias eram de fácil consenso, tais como mesmas garantias do Poder Judiciário, independência funcional, irredutibilidade de vencimentos etc.

No entanto, não havia consenso em outras questões polêmicas, tais como eleição para Procurador-Geral e também quanto à possibilidade ou não do exercício simultâneo da advocacia.

Alguns acreditavam que a Carta de Curitiba não seria aprovada, o que já era, porém, um gran- de avanço. Mas a Constituinte foi muito além dela - a Carta de Curitiba era considerada um sonho irrealizável. No entanto, o final foi vitorioso, pois a Constituição Federal de 1988 já delineava a instituição de forma muito superior à própria Carta de Curitiba.

Por essa e outras razões, na opinião de alguns, como por exemplo, Araldo Dal Pozzo, logo a Carta de Curitiba ficou anacrônica - pois posteriormente conseguiu-se mais na Constituinte.

\section{A ATUAÇ̃̃O CONCRETA DOS PROMOTORES E PROCURADORES NA ANC}

Cabe aqui apontar como se deu a atuação concreta de representantes do Ministério Público na Assembleia Nacional Constituinte: como eram as idas até Brasília, quem eram os contatos no Congresso Nacional, que alianças fizeram, que propostas levaram para serem votadas, o que ganharam e o que perderam.

Plínio Arruda Sampaio (2002), relator do anteprojeto quanto à parte referente ao Ministério Público, com a instalação da constituinte, requisitou para seus assessores Luis Antônio Guimarães Marrey, Plínio Gentil e Claudio Brochetto, que haviam desenvolvido uma tese em um congresso da CONAMP sobre o Ministério Público. O trabalho de Plínio na ANC foi extremamente importante, pois consistiu na construção de alianças para permitir a aprovação de um texto que já havia sido discutido previamente pela classe que surgiu a partir da Carta de Curitiba.

Já se tinha, então, uma ideia do que deveria a Constituição contemplar em termos de Ministério Público. Nesse aspecto, a Carta de Curitiba foi de grande valia porque, segundo Plínio de Arruda Sampaio (2002, p. 28): 
A verdade é a seguinte: a Constituinte não é o lugar das discussões teóricas, não há clima para isso, pois a velocidade e o sistema de negociação impedem a elaboração teórica. 0 importante é o que está amadurecido na sociedade. O Ministério Público, por exemplo, teve esse êxito porque a idéia estava amadurecida na sociedade, porque os promotores nos diversos lugares do Brasil criaram uma hegemonia, por meio da ação de suas associações, de seus congressos, das suas teses, das suas publicações, da circulação de toda essa efervescência cultural e discursiva. Ora, os setores com amadurecimento conseguiram seu lugar na Constituinte. 0 que não estava alicerçado por uma hegemonia alcançou resultados mais pobres.

0 momento mais importante, qual seja, o de acompanhar na Constituinte as reivindicações feitas pelos promotores, chegara. Para tanto, foi efetuada uma mobilização entre os membros de Ministério Público de diversos Estados, para que acompanhassem os trabalhos na ANC e mantivessem contato com os congressistas a quem tivessem algum acesso. No relato de Hugo Nigro Mazzilli (2002, p. 16):

[...] Sob esse aspecto, o Ministério Público começou a fazer uma grande mobilização, já com vistas a se preparar para as reivindicações que deveríamos fazer na Constituinte. Considero que todos os membros do Ministério Público estavam e se sentiam mobilizados. Bom, foi nesse momento que começou mais diretamente o acompanhamento dos trabalhos na Constituinte. Todos os Estados contribuíram muito para isso, porque, então, passou a haver mais harmonia, a partir de um texto básico aprovado por todas as lideranças do Ministério Público brasileiro. Em Brasília, os diversos Ministérios Públicos Estaduais se faziam presentes. Ficávamos direto lá, 24 horas por dia, todos os dias da semana. Desde a abertura dos trabalhos da Constituinte até mesmo depois da promulgação da Constituição de 1988, havia membros do Ministério Públido, de praticamente todos os estados, acompanhando os trabalhos parlamentares em Brasília.

Ainda que elaborado a partir de um projeto de consenso, a tarefa de convencer o constituinte não era sobremaneira fácil. A uma, porque o constituinte raras vezes tinha algum conhecimento sobre a instituição Ministério Público, a necessidade de garantias, prerrogativas, forma de investidura dos procuradores-gerais, a consequencia de uma ou outra escolha etc. A duas, porque se buscava junto ao constituinte a atribuição ao Ministério Público de uma feição até então inédita em âmbito nacional, que prometia maior rigidez no combate à corrupção, aos danos ao meio ambiente, dentre outros, por meio do fortalecimento de instrumentos como o inquérito civil e a ação civil pública, o que poderia não agradar a alguns congressistas.

0 primeiro empecilho - o desconhecimento da instituição - foi superado com o corpo a corpo junto aos constituintes, mediante o auxílio de uma cartilha explicativa sobre o Ministério Público, que consistiu em um verdadeiro manual para os constituintes. Visava mostrar aos constituintes a essência da Instituição 'Ministério Público'. A intenção, segundo os relatos orais observados, era mostrar ao congressista que o Ministério Público não é só aquele que processa criminalmente alguém - às vezes isso acontece, é preciso - mas ele também é aquele que defende o cidadão, que dá apoio às políticas públicas criadas pelo próprio Congresso.

Já o segundo empecilho, qual seja, a atribuição ao Ministério Público de uma feição até então inédita em âmbito nacional e internacional, que prometia maior rigidez no combate à corrupção, aos danos ao meio ambiente, dentre outros, por meio de instrumentos como o inquérito civil e a ação civil pública, o que poderia não agradar a alguns políticos, foi um obstáculo mais difícil de ser superado.

No comando direto dos trabalhos na Constituinte, Araldo Dal Pozzo contou com a ajuda de colegas para, como dito pelo próprio, "vender aquele peixe", julgando inclusive se tratar de um "[...] peixe difícil de vender, porque prometíamos fiscalização, controle, cadeia. Artigos difíceis de se vender. Precisávamos ter muito engenho e arte para vender tais idéias" (DAL POZZO, 2002, p. 9). 
O Ministério Público contava com dois integrantes da instituição que ocupavam mandatos parlamentares, totalmente solidários no tocante à missão, como o gaúcho Ibsen Pinheiro, reconhecido por muitos como 'dono de aguda inteligência e enorme capacidade de síntese e articulação', que pertencia ao Ministério Público do Rio Grande do Sul; e Plínio de Arruda Sampaio, militante da esquerda, havia sido promotor de Justiça no Estado de São Paulo, cassado pelo regime militar, tendo sido ainda o primeiro relator da Subcomissão do Poder Judiciário e do Ministério Público, assumindo, neste contexto, papel de negociador, dentre outros parlamentares não menos importantes neste processo.

Assim, procurou-se desenvolver mecanismos internos de atuação, por meio do contato com os congressistas - mapeamento e trabalho de inteligência - a fim de que fosse possível explicar o que era o Ministério Público e porque aqueles tópicos do projeto eram importantes, a fim de vencer eventuais resistências (DAL POZZO, 2002, p. 5, grifo nosso):

Essa evolução nasceu graças a uma discussão permanente que fazíamos, captando ideias, tendo ideias, mas buscando entender aquilo que circulava pelos corredores do Congresso e, em especial, as deficiências do regime democrático que se pretendia construir decorrentes de um sistema que inicialmente se pretendia parlamentarista e depois mudado para o presidencialismo. Essa foi uma brecha importante que divisamos, pois essa metamorfose ocorreu no meio do caminho. Mas, de qualquer maneira, sempre que detectávamos um ponto fraco no estudo do mecanismo democrático que se desenhava, quando sentíamos uma deficiência, encontrávamos uma maneira de colocar o Ministério Público no meio. Aquele rol de atribuições institucionais que estão na Constituição, são, vamos dizer assim, o preenchimento de lacunas nos sistemas de controle dentro do Estado democrático que se procurava criar. [] Esse é um exemplo muito claro de como conseguíamos escrever essas coisas no texto da Constituição. Com o passar do tempo, essa idéia virou quase um hábito na Constituinte: na dúvida, coloca-se o Ministério Público. Mas, houve um momento em que tivemos que começar a cortar atribuições, porque, também, não dava para fazer tudo que queriam. Enfim, foi essa a maneira pela qual conseguimos vender a idéia do Ministério Público, como sendo aquele que queria fazer o que, no Estado Brasileiro anterior, não se encontrava quem fizesse. Brincávamos que àquela época se dizia: "Vai reclamar para o Bispo!”... e nós queríamos ser esse "Bispo" .... Quer dizer, a entidade, o braço da sociedade que recebe poder para fazer e faz. Essa foi a estratégia. A estratégia de conhecer as pessoas e de colocar as questões dentro do texto.

Desta forma, as ideias sobre o Ministério Público passaram a ganhar força na Constituinte de tal forma que a própria Carta de Curitiba foi tida como ultrapassada. Surpreendentemente, a Assembleia Nacional Constituinte foi muito além dela. A autonomia administrativa e financeira, que não consta da Carta, é um dos aspectos deste avanço.

Por outro lado, percebidas as deficiências do regime democrático, logo se inseria a figura do Ministério Público, de tal sorte que o rol de atribuições institucionais que se encontra na Constituição Federal é um preenchimento de lacunas nos sistemas de controle desse regime.

Sabe-se que, numa perspectiva histórica, o Ministério Público foi originalmente concebido para defender os interesses do Monarca. Porém, o que se pretendia na ocasião era dissociar definitivamente o Ministério Público da defesa dos interesses do Estado. A grande questão passou a ser o interesse social. Como consequência, "acabou sendo produzido um texto, vamos dizer assim, super avançado, como não há no mundo outro similar; nenhuma Constituição que tenha um texto sobre o Ministério Público tão avançado quanto esse" (DAL POZZO, 2002, p. 15).

Mas esse processo não foi fácil. Houve muitas resistências no caminho. A título de ilustração, apenas, veja-se um panfleto apócrifo distribuído na ANC sobre o projeto referente ao Ministério Público: 
Figura 1 - Panfleto apócrifo, distribuído por ocasião da Assembleia Constituinte

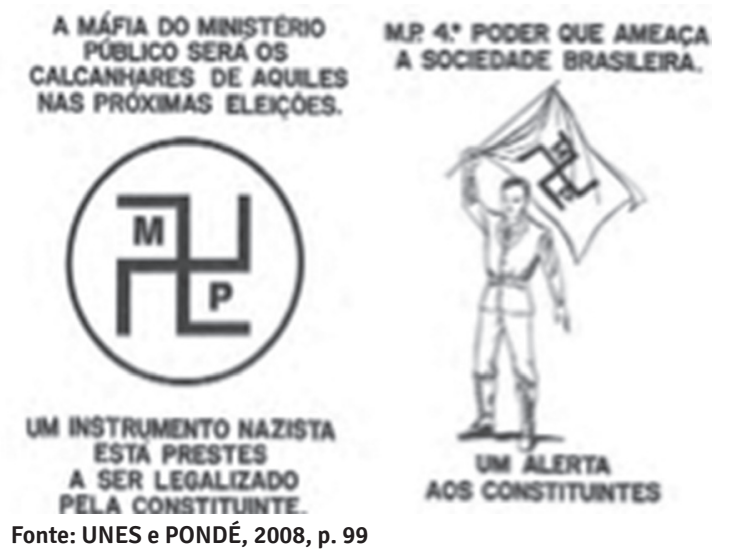

Além das resistências de alguns congressistas, enfrentou-se, em determinados momentos, outros óbices por parte dos Delegados de Polícia e da Magistratura quanto ao texto pretendido pelo Ministério Público.

As resistências dos Delegados de Polícia giravam em torno, principalmente, da questão da equiparação salarial, da paridade e do controle externo. A classe policial pretendia ver seus vencimentos equiparados aos dos Promotores de Justiça, o que sempre foi rechaçado por esta classe, pois seriam inevitavelmente diminuídos ao longo do tempo. Ao final, conseguiu-se afastar essa equiparação do texto constitucional. Outra resistência com esta classe foi a questão do controle externo da atividade policial, afeta ao Ministério Público, que sofreu grande resistência por parte dos Delegados de Polícia.

Com a Magistratura, também, houve algumas questões que separavam as classes. Uma delas era a equiparação de vencimentos pretendida pelo Ministério Público - e rechaçada pelos juízes. Outro ponto de atrito foi a questão do Juizado de Instrução, que transformava os Delegados de Direito em Juízes de Instrução, o que era inaceitável por parte do Poder Judiciário. Ao final, houve um consenso entre as ins- tituições e a resistência à equiparação foi abandonada pelo Judiciário e a ideia dos juízes de instrução foi abandonada pelo Ministério Público, passando a andar as duas instituições de maneira mais afinada.

Quanto aos pontos de atrito com o Poder Executivo, pelos atores que participaram deste processo, foi apontado apenas um: a questão da nomeação do Procurador-Geral, que o executivo nunca abriu mão e ao final, saiu vencedor. A ideia do Ministério Público era a de acabar com essa ingerência na instituição, o que enfrentou grande resistência do Poder Executivo, que queria tanto nomear como demitir o chefe da Instituição. Ao final, restou aprovado que o Procurador-Geral seria nomeado pelo executivo (o que não era desejado pela classe), mas dentre integrantes da instituição, por mandado por prazo certo, sem possibilidade de demissão, o que minimizaria a ingerência do executivo.

Ao final, os trabalhos da constituinte sofreram um revés. No decorrer de todo o processo - não apenas no que tange ao Ministério Público - foram inegáveis as conquistas que os setores de esquerda estavam angariando, o que acabou por provocar uma reação - por meio do denominado 'Centrão', que repercutiu também nas conquistas até então obtidas pelo Ministério Público. No dizer de Mazzilli (2011, p. 15):

Surgiu uma reação inesperada para nós; talvez para políticos mais experientes isso não fosse surpresa, mas para o Ministério Público foi, porque, de uma hora para outra, tudo o que nós tínhamos feito, tudo o que nós tínhamos conseguido fosse aprovado até ali, tudo aquilo para o qual nós tínhamos trabalhado e tudo o que tínhamos obtido com muito sacrifício, acabou sendo retirado do texto, por força do substitutivo oferecido pelo movimento conhecido como "Centrão", ou seja, um novo texto, fruto da reação dos Constituintes ligados a ' posição mais conservadora. Todo aquele enorme esforço parecia ruir para nós: tínhamos vencido as oposições dentro do próprio Ministério Público; tínhamos vencido as resistências dos parlamentares, tínhamos conseguido inserir diversos dispositivos de inegável importância para as garantias institucionais nos textos das comissões anteriores - e, depois, aconteceu que de uma hora para 
outra o movimento político conhecido na época como "Centrão" virasse tudo. Um grupo de parlamentares conservadores, e, em certos pontos até reacionários, elaborou um novo anteprojeto para todos os trabalhos constituintes, e derrubou, com uma só penada, todo o texto que já tinha sido elaborado até ali, propondo um substitutivo global.

Por força desse substitutivo apresentado, o plenário estava para aprovar o texto do "Centrão", apenas com modificações referentes a destaques. Esse projeto para o Ministério Público era péssimo. Nesse momento, havia algumas alternativas: aguardar a aprovação do texto apresentado pelo "Centrão", que representava um retrocesso em relação à tudo que foi conseguido, ou então procurar algum parlamentar para apresentar um destaque, que, na realidade, deveria praticamente reformar todo o capítulo referente ao Ministério Público. O risco seria cair o texto do "Centrão" e nada restar ao Ministério Público, o que seria ainda pior, porque a instituição seria tratada pelo legislador infraconstitucional.

Os atores envolvidos, então, optaram por apresentar o destaque. Aconteceu o pior: o texto do "Centrão" caiu e o Ministério Público ficou sem nada. Nesse momento, no dizer de Mazzilli (2011, p. 15):

E parlamentares nossos aliados apresentaram o destaque e foi derrubado o texto do "Centrão"... e ficamos sem nada. Aí, passamos a articular com as lideranças políticas o texto que entendíamos viável àquela altura, ou seja, a conciliação de todo o material que até então tinha sido produzido: a Carta de Curitiba, o anteprojeto da Comissão Afonso Arinos, o anteprojeto de Arruda Sampaio, o texto do relatório de Bernardo Cabral, anterior ao "Centrão", e o texto do "Centrão"... Pegamos tudo, fizemos os melhores ajustes possíveis dos princípios, das funções, das garantias, de tudo, enfim, e tentamos ainda conciliar a posição dos vários Constituintes que já tinham apresentado diversos destaques específicos na parte do Ministério Público. E conseguimos. Os destaques foram aglutinados por emenda conjunta coordenada pelo Ibsen Pinheiro, pelo Theodoro Mendes, pelo Fábio Feldman, pelo Carlos Vinagre, pelo Jalles Fontoura... Havia outros parlamentares, mas estou falando de memória... Fizemos isto e fomos aguardar a decisão do Plenário da Constituinte, pois a aprovação dos destaques tinha de ocorrer em Plenário. $\mathrm{E}$, finalmente, o novo texto referente ao Ministério Público foi aprovado! Eu estava em Brasília naquele dia, estava no Congresso e eu assisti à votacão. Foi uma votação emocionante, porque era todo um trabalho de gerações de Ministério Público que estava lá em jogo naquele momento, e o resultado iria orientar o trabalho da Instituição por muitos anos para o futuro.

Esses foram, portanto, os principais aspectos que permearam o processo da atuação concreta dos representantes do Ministério Público na Assembleia Nacional Constituinte, até a aprovação final do texto.

\section{VITÓRIAS E DERROTAS}

Neste tópico, procuraremos elencar, de modo sucinto, quais foram as principais vitórias e as principais derrotas do Ministério Público na Assembleia Nacional Constituinte e qual a avaliação feita pelos principais atores deste processo sobre o texto final da Constituição de 1988, em termos de mudanças no Ministério Público.

Como já visto, desde 1985 já se falava na Assembleia Nacional Constituinte e até então, duas grandes questões dividiam o Ministério Público: o exercício da advocacia e a forma de escolha do Procurador-Geral. Ambas as questões representavam pontos de divergência dentro da própria instituição.

A advocacia era um forte ponto de resistência. $\mathrm{Na}$ prática, ser um "promotor-advogado" significava manter uma concorrência desleal com os demais advogados, visto que as atribuições confundem-se em uma só pessoa, de promotor - e, portanto, agente político - e de advogado.

[...] vários Ministérios Públicos Estaduais e o Ministério Público Federal conservavam o direito de exercer a advocacia. Promotores, Procuradores, todos advogavam. E nós defendíamos ardentemente a bandeira da não-advocacia, porque, por todos os títulos, ela, evidentemente, não se justificava. Hoje, olhando para trás, e faz tão pouco tempo, não podemos nem imagi- 
nar que se cogitava uma coisa tão absurda como essa. No entanto, era uma luta tremenda entre os que queriam conservar esse direito e os que, como nós, eram contra (DAL POZZO, 2002, p. 6).

Mais do que isso, na prática, o exercício da advocacia representaria “desequiparação" - de certa forma ilegítima - com a Magistratura. Não há razão para o promotor receber o mesmo que o juiz e poder simultaneamente advogar, pois, ao exercer a advocacia, já complementaria sua renda. Ademais, o promotor é prestigiado na comarca em que atua e possuiria um relevante diferencial competitivo. Os estados que conquistaram a equiparação de vencimentos com a Magistratura foram aqueles que renunciaram ao direito de advogar.

Já no assunto referente ao exercício da advocacia, ganhamos bonito. Não tinha efetivamente nenhum sentido um promotor, que é uma autoridade pública, entrar numa Vara como autoridade num dia e entrar como postulante no outro. Isso não tinha propósito, pois a vantagem sobre o colega advogado era brutal, pois enquanto um tem, ao despachar, lugar cativo junto ao juiz, o outro só entra em contato com o magistrado no dia da audiência. (SAMPAIO, 2002, p. 10).

O Rio de Janeiro foi ferrenho defensor do direito à advocacia, por intermédio de Navega, presidente da associação, Biscaia, Procurador-Geral e Sérgio D’Andrea Ferreira, jurista, Procurador de Justiça, dono de uma banca de advocacia de renome e professor de Direito Administrativo.

Já na aprovação da Carta de Curitiba, muito foi discutido quanto à possibilidade ou não do exercício da advocacia por parte dos promotores. Ao final, a classe assumiu o compromisso de defender, junto à ANC, a vedação da advocacia.

No entanto, alguns promotores que desejavam manter essa prerrogativa, insistiram em manter essa possibilidade na Constituição, mesmo contra o que havia sido decidido pela classe em Curtiba. E, em sentido contrário, aqueles que entendiam incompatíveis tais funções, defenderam seu posicionamento perante os congressistas. Ao final, o embate foi vencido da seguinte forma: assegurou-se a equiparação de vencimentos dos promotores de justiça aos dos membros do poder judiciário e, por outro lado, instituiu-se a proibição de exercer a advocacia.

Outra questão polêmica versou quanto à escolha do Procurador-Geral. Nesse aspecto, para Araldo, não houve avanços, porque "foi um ponto em que não conseguimos avançar como queríamos, porque nossa ideia era terminar com essa interferência do Executivo na nomeação" (DAL POZZO, 2002, p. 25).

Além disso, o perfil autônomo e independente do Ministério Público relevou ser uma ameaça à classe política - "percebi que os políticos somente não tiram o Ministério Público do texto da Constituição porque não têm condições políticas para fazerem isso; mas ninguém gosta do Ministério Público" (DAL POZZO, 2002, p. 28).

Essa ingerência do executivo, praticamente, acabou no texto constitucional, de forma que cabe ao chefe do poder executivo apenas a nomeação do procurador-geral. No entanto, essa ingerência restou suavizada pelo fato de que o escolhido deveria ser integrante da carreira (antes esse requisito não existia, qualquer um poderia ser nomeado chefe do ministério público); deveria ser integrante de uma lista tríplice escolhida pela instituição e teria mandato de dois anos (o que representou um avanço, posto que em muitos ministérios públicos o procurador-geral era demissível ad nutum pelo governador.

Um outro embate digno de nota foi a possibilidade ou não de os promotores de justiça exercerem atividade político-partidária. Alguns eram favoráveis a essa possibilidade; outros, contra. Ao final, venceu uma posição intermediária: somente aqueles promotores que ingressaram antes de 1988 poderiam exercer tal atividade. 
Segundo Plínio de Arruda Sampaio (2002), a sua única derrota foi aquela que proibia ao promotor o exercício da atividade político-partidária. Para ele, deveria permanecer a incompatibilidade de funções. Até a Constituição de 1988, ficou estabelecido o meio termo, havia a chamada "classificação em Quadro Especial”, que, ao poucos, eliminaria a atuação político-partidária dos promotores.

\begin{abstract}
A propósito, creio que, em nosso capítulo, fui derrotado apenas em um ponto, aquele que vedava ao promotor a atividade político-partidária, tema pelo qual me bati, por um compromisso moral, já que era deputado e entendia ser inconveniente o acúmulo de funções. Eram outros tempos, o Brasil era outra coisa, o Ministério Público era das poucas reservas morais e intelectuais de que dispúnhamos. Mas a razão real da oposição à minha emenda não era essa. Uma vez perguntaram-me: 'Você quer cassar o Ibsen Pinheiro?' - pois o Ibsen era Promotor Público - ao que respondi: 'Não se trata de cassar Fulano ou Beltrano, mas de uma questão de princípios' Mas eu perdi, no voto, e surgiu aquela norma... Como se chama? Memorial GA: A classificação em Quadro Especial, não é? Entrevistado: Sim, a turma do Quadro Especial, que vai acabando, acabando, acabando e, finalmente, vai valer o outro princípio. (SAMPAIO, 2002, p. 7).
\end{abstract}

Outro tema polêmico era o controle externo da atividade policial. Inicialmente, Plínio pretendia um controle mais amplo, isto porque, sendo o Ministério Público o titular da ação penal, era justo que a Polícia investigativa pertencesse à instituição, sendo-lhe inteiramente subordinada, uma vez que a Polícia é a responsável por preparar as primeiras evidências para que o Ministério Público se mobilize e ingresse em juízo (SAMPAIO, 2002).

Sob outro aspecto, no tocante às teses extremistas, Plínio (2002) seguia a orientação de que, em que pesem as circunstâncias históricas, avanços muito proeminentes - para os quais o país não tinha preparo - resultariam em letra morta na Constituição, ao passo que construções ponderadas seriam posteriormente estendidas pela jurisprudência e pela lei infraconstitucional. "Enfim, muitas coisas terminaram entrando na Constituição por causa desse quadro circunstancial de vacilação das elites dominantes. As elites estavam desprovidas de lideranças fortes" (SAMPAIO, 2002, p. 22).

Houve ainda a ideia do ombudsman, que havia surgido na Confederação Nacional dos Bispos do Brasil (CNBB), intentava-se criar um Ouvidor-Geral da República. Para Plínio, porém, “um ouvidor demandaria uma burocracia para chegar nele que inviabilizaria sua função" (SAMPAIO, 2002, p. 24).

\begin{abstract}
Memorial - RVS: E essa função de ombudsman o Ministério Público já desempenhava empiricamente. Entrevistado [PLÍNIO]: Sem dúvida, há muito tempo. Enfim, ests proposta não prosperou. O próprio Dom Vicente concluiu que não daria certo. Num ou noutro documento da CNBB chegou a sair alguma "coisinha" defendendo a proposta, mas no cômputo geral, não teve peso decisório.
\end{abstract}

Houve, assim, um movimento forte da sociedade para a criação da figura independente do ombudsman, similar à dos países escandinavos. Essa proposta desejava uma instituição independente para exercer tais funções. Ao final, o Ministério Público acabou por absorver essa demanda, avocando para si também tais funções.

Essas foram as principais questões discutidas no âmbito da ANC, que acabaram por resultar em derrotas ou vitórias para a instituição. Ao final, os atores participantes desse processo, em geral, avaliam positivamente o texto constitucional, que representou um avanço para a instituição e para a sociedade. Poucas foram as derrotas sofridas pela instituição, destacando-se, entre elas, como principais, a escolha do procurador-geral pelo chefe do poder executivo, o que ainda representa certa ingerência na instituição e a possibilidade àqueles que ingressaram nos quadros do Ministério Publico antes de 1988, de exercerem atividade político-partidária.

Sobre o saldo de todo esse processo, bem sintetiza Mazzilli (2010, [s.p.]): 
O que me parece ter sido o principal saldo foi o seguinte: o Ministério Público saiu da Constituição de 88 com um perfil totalmente novo. Organizado num Capítulo à parte, não foi erigido a um Poder de Estado, embora tenha todas as garantias de Poder; teve suas principais funções e garantias institucionais reconhecidas pelo próprio Constituinte. Principalmente, o Ministério Público brasileiro veio a ter delineado um novo papel na sociedade, e essa foi a razão pela extrema mudança de atuação pela qual a Instituição tem passado a partir de então, em razão do que está desempenhando funções muito mais ativas e eficientes no combate ao crime organizado, na defesa do meio ambiente, no combate à improbidade administrativa e no zelo de direitos constitucionais.

\section{POR QUE UM TEXTO CONSTITUCIONAL TÃO AVANÇADO?}

Inquestionável a mudança na feição do Ministério Público com o advento da Constituição de 1988. Como já apontado acima, na observação de Mazzilli, o Ministério Público teve o grande mérito de desejar uma nova feição com a Constituição de 88. Nenhuma outra instituição ligada à Justiça mudou tanto. A magistratura, a advocacia, os delegados de polícia, todas essas classes mantiveram mais ou menos sua mesma feição, com algumas poucas modificações.

Na sempre lúcida observação de Mazzilli (2011, [s.p.]) em entrevista concedida ao Memorial do MP/ SP:

O Ministério Público teve o mérito, a meu ver, de ter sentido isto, de também ter querido mudar, e, verdade seja dita, o Ministério Público realmente foi a única instituição ligada à Justiça que realmente quis mudar de forma efetiva. Veja que, depois da Constituição de 1988, a Magistratura continuou praticamente como era; não me refiro à sua estrutura organizacional ou a aspectos secundários, mas sim quero dizer que a estrutura filosófica da Magistratura não mudou. Por sua vez, a Advocacia não mudou seus princípios ou sua filosofia a partir de 1988. Mas, antes de 88 e depois de 88, são dois Ministérios Públicos diferentes. Estávamos, pois, vivendo esse período de fim de ditadura militar; já havia começado a abertura política, e o
Ministério Público vinha buscando novas atribuições, mais espaço para atuação, funções de cunho mais social, e não apenas funções meramente interventivas ou processuais.

Assim, de fato, se olharmos para o Ministério Público antes e depois da CF, notaremos duas instituições completamente diferentes. Como se deu esse processo para aprovação de um texto constitucional revolucionário e único no mundo já foi visto no tópico acima. Resta-nos questionar, agora, como foi possível a aprovação de um texto com tais características na ANC, texto tão avançado ao final, que superou até mesmo as expectativas da própria classe.

Para explicar a aprovação de um texto que atribui ao Ministério Público funções que extrapolam a persecução penal, algumas teses são levantadas, dentre elas: a) a de que os constituintes não possuíam a dimensão exata do que estavam aprovando; b) a de que o lobby dos promotores foi muito forte e 'enganou' os parlamentares; c) a de que a aprovação se deu graças a um aspecto conjuntural decorrente da própria ANC, que reflete um contexto histórico-político favorável.

\section{Analisemos estas teses.}

A afirmação de que os congressistas foram 'enganados' devido a um forte lobby não se sustenta. A uma, porque se havia lobby da Confederação Nacional do Ministério Público, houve, igualmente, lobby de outras classes ligadas à Justiça - associações de magistrados, de delegados de polícia etc. Assim, se todas as instituições fizeram lobby, por que foi o Ministério Público que recebeu as maiores modificações? Assim, a questão da pressão de classe não explica, por si só, a aprovação do texto constitucional.

De fato, percebe-se, como explanado acima, que o papel da CONAMP foi extremamente eficaz, na medida em que ofereceu ao constituinte um projeto fruto do consenso entre os membros da classe, consubstanciado pela Carta de Curitiba e desenvolveu um tra- 
balho de minucioso acompanhamento das discussões e das votações na ANC.

No entanto, apenas essa pressão não seria suficiente para fazer aprovar um texto constitucional como o que se viu ao final.

Ao final, percebe-se que foi possível "vender o peixe" justamente porque as propostas não tratavam de uma visão meramente corporativista, mas sim de atribuições e garantias postas para defender a lei.

A Constituinte é uma transação, com a maioria dos deputados representando setores muito corporativos. Quando um grupo surgia com uma pretensão clara e bem articulada, o outro lado, caso a proposta não interferisse no seu campo de interesses mais diretos, preferia agradar ao relator, a fim de contar em seguida com a boa vontade do mesmo em alguma questão corporativa mais específica. (SAMPAIO, 2002, p. 26-27).

Na visão de Fábio José Kerche Nunes, quanto à aprovação do texto, o que se discute é motivo que levou os constituintes de 1987-1988 a optarem pelo modelo de Ministério Público que se conhece hoje. Isto porque, no Direito comparado, a instituição brasileira é notadamente distinta do que se verifica na maioria dos países democráticos. Sua hipótese é a de que (NUNES, 2010, p. 9):

[...] verificou-se, de fato, uma eficiente organização da Confederação Nacional do Ministério Público que ofereceu aos constituintes uma proposta em forma de texto constitucional (a "Carta de Curitiba") sobre a inclusão do parquet na Constituição e desenvolveu um trabalho de acompanhamento junto às discussões constituintes (lobby) que se mostrou eficaz. Por outro, houve relativa facilidade para esse lobby operar "vendendo" aos constituintes a ideia da importância da criação de um agente não político - ou pelo menos, não político partidário - responsável pela defesa de interesses da sociedade. Essa relativa facilidade se deve a um aspecto conjuntural e a características de cultura política.

O aspecto conjuntural consiste no fato de que os trabalhos da Assembleia Nacional Constituinte se de- ram em um período pós-ditadura, por isso, buscava-se uma democratização, ou seja, um fortalecimento institucional em contraposição ao regime militar. Tanto é verdade que se observaram, no texto Constitucional, vários aspectos com este viés, citando-se, exemplificativamente, a ampliação dos direitos coletivos e a instituição do referendo e do plebiscito. Nesse sentido:

\begin{abstract}
A turma de São Paulo tinha uma delegação forte de negociadores na Constituinte, composta, entre outros, pelo Fleury, pelo Araldo Dal Pozzo, pelo Hugo Mazzilli [...] O Sabella [...] Consultei, também, outros juristas, com os quais tenho uma estreita ligação, tais como o Geraldo Ataliba, o Zé Afonso, o Luiz Antônio, o Luís Antônio Bandeira de Melo, o Fábio Comparato. São todos grandes constitucionalistas. Manifestando consideração pelo capítulo, disseram-me: "Isto precisa ser feito!". Trata-se, creio, de uma inovação constitucional, com a criação quase de um outro Poder. Parece-me que este aspecto não chegou a ser ainda estudado com vagar, pois a doutrina dos três Poderes afigura-se tão poderosa, tão ortodoxa... Talvez seja o passo agora a ser dado, isto é, a constitucionalização total do Ministério Público". (SAMPAIO, 2002, p. 8).
\end{abstract}

Assim, pode-se afirmar que os congressistas não foram 'enganados' sobre o que o Ministério Público pretendia fazer inserir na Constituição, tampouco foi obra de lobby dos promotores - todas as classes o fizeram.

Foi, sim, fruto de um momento conjuntural histórico-político vivido pelos constituintes - estavam vivendo o fim da ditadura militar iniciada em 1964 e havia uma expectativa da sociedade - e dos congressistas - de uma mudança política e institucional no país, o que favoreceu a aprovação de um texto constitucional progressista, inclusive na parte referente ao Ministério Público, daí a explicação para a aprovação de um texto constitucional tido como progressista.

\section{CONSIDERAÇÕES FINAIS}

0 presente artigo teve por escopo perscrutar as informações disponíveis sobre a atuação de atores do Ministério Público na Assembleia Nacional Cons- 
tituinte. Considerando que recentemente houve o advento de comemoração dos 25 anos da promulgação da Constituição da República Federativa do Brasil, por alguns denominada de 'Constituição-cidadã', e que, nesse período, o Ministério Público brasileiro desenvolveu uma feição única no espectro mundial, em muito resultado do quanto preconizado no texto constitucional, útil neste momento trazer à colação informações já disponíveis, notadamente entrevistas, de modo a registrar a preparação, atuação e conquistas do Ministério Público na ANC e, ao final, o desenho constitucional obtido.

Assim, procurou-se obter informações, notadamente de fontes orais, sobre a agenda do Ministério Público para a ANC, quais as pessoas que se mobilizaram nestes trabalhos, quais candidatos foram procurados, como se deu essa abordagem e quem eram os principais contatos no Congresso Nacional. Também, procurou-se investigar quais alianças foram firmadas, quais propostas foram levadas para votação, quais as vitórias e quais as derrotas decorrentes dessa atuação. Ao final, procurou-se perscrutar qual a avaliação do texto final da Constituição de 1988 por esses atores e como foi possível a aprovação no Congresso.

A partir do início do fim do governo militar, e com o advento de uma promessa de uma nova ordem constitucional, o Ministério Público percebeu a necessidade de não assistir esse processo de maneira estanque. As lideranças nacionais do Ministério Público se aperceberam de que essa nova ordem constitucional deveria ser proposta a partir de reflexões geradas pela própria instituição. Os promotores decidiram participar ativamente da construção dessa nova feição do Ministério Público.

A atuação da CONAMP e de diversos membros do Ministério Público foi decisiva para este processo, aliado à conjuntura histórico-política vivenciada naquele momento.

Inquestionável a mudança na feição do Ministério Público com o advento da Constituição de 1988. Como já apontado acima, na observação de Mazzilli, o Ministério Público teve o grande mérito de desejar uma nova feição com a Constituição de 1988. Nenhuma outra instituição ligada à Justiça mudou tanto. A magistratura, a advocacia, os delegados de polícia, todas essas classes mantiveram mais ou menos sua mesma feição, mas com algumas poucas modificações, diferentemente do que ocorreu com o Ministério Público nesse momento histórico.

Conclui-se, portanto, que a aprovação do texto constitucional referente ao Ministério Público deveu-se a dois fatores preponderantes, quais sejam: a organização da instituição para levar um projeto de consenso ao constituinte, consubstanciado na denominada Carta de Curitiba; e o momento conjuntural histórico-político, representado pelo desejo do constituinte, em um período pós-ditadura, de fomentar a consolidação de uma instituição democrática forte em contraposição ao regime militar.

\section{REFERÊNCIAS}

CARTA de Curitiba. 1986. Disponível em: <http:// www.conamp.org.br/Acesso\%20Pblico/Congresso $\% 20 \mathrm{Nacional} \% 20 \mathrm{do} \% 20 \mathrm{MP} \% 20$ - \%20 Cartas\%20PDF/Carta\%20de\%20Curitiba.pdf>. Acesso em: 4 maio. 2014.

DAL POZZO, A. A. F. Antonio Araldo Ferraz Dal Pozzo: depoimento. [9 de maio de 2012]. São Paulo. Entrevista concedida ao Memorial do Ministério Público do Rio Grande do Sul com a participação do Procurador de Justiça Ricardo Vaz Seelig.

KERCHE, F. O Ministério Público e a constituinte de 1987/88. In: SADEK, MT, (org.). O sistema de justiça [on-line]. Rio de Janeiro: Centro Edelstein de Pesquisas Sociais, 2010. 0 sistema de justiça. p.106-137.

MAZZILLI, H. N. Hugo Nigro Mazzilli: depoimento. [21 de novembro, 2011]. São Paulo. Entrevista conce- 
dida a Dr. Alexandre Rocha Almeida de Moraes, Dra. leda Casseb Casagrande Bignardi, Dr. Ruy Alberto Gatto e Dr. Walter Paulo Sabella.

MAZZILLI, H. N. Depoimento. [12 de jun. 2002]. Entrevista concedida ao historiador Gunter Axt.

MAZZILLI, H. N. A carta de Curitiba e a Constituinte. Disponível em: <http://www.mazzilli.com.br> Acesso em: 10 mar. 2015.

MAZZILLI, H. N. Introdução ao ministério público. São Paulo: Saraiva, 2002.

SABELLA, Walter Paulo. Ministério Público, 25 anos depois: depoimento. [set. 2013] Revista Tribuna do Direito. São Paulo, 2013. Entrevista concedida à Revista Tribuna do Direito (TD).
SABELLA, Walter Paulo. O MP na Constituinte da CR/88. Carta Forense. 2008. Disponível em: <http://www.cartaforense.com.br/conteudo/entrevistas/o-mp-na-constituinte-da-cr88/1850>. Acesso em: 9 maio 2012.

SABELLA, Walter Paulo. A história do Ministério Público: algumas lutas e passagens. Brasília: Escola Superior do Ministério Público, 2002.

SAMPAIO, P. A. Plínio de Arruda Sampaio: depoimento. [7 de ago. de 2002]. São Paulo. Entrevista concedida ao historiador Gunter Axt (GA) e ao Procurador de Justiça Ricardo Vaz Seelig.

UNES, W.; PONDÉ, R. (Org.). Memória do Ministério Público em Goiás. Goiânia: Instituto Centro-Brasileiro de Cultura, 2008. 